\title{
ELECTRICAL RESISTIVITY OF STRONGLY COUPLED PLASMAS IN INTENSE FIELDS
}

\author{
R. Cauble \\ F. J. Rogers \\ W. Rozmus \\ This Paper was Prepared for Submittal to \\ Yamada Conference on Strongly Coupled \\ Plasma Physics \\ Tokyo, Japan \\ $8 / 28 / 89$
}

August 1989

This is a preprint of a paper intended for publication in a journal or proceedings. Since changes may be made before publication, this preprint is made available with the understanding that it will not be cited or reproduced without the permission of the author.

\section{DISCLAIMER}

This report was prepared as an account of work sponsored by an agency of the United States Government. Neither the United States Government nor any agency thereof, nor any of their employees, makes any warranty, express or implied, or assumes any legal liability or responsibility for the accuracy, completeness, or usefulness of any information, apparatus, product, or process disclosed, or represents that its use would not infringe privately owned rights. Reference herein to any specific commercial product, process, or service by trade name, trademark, manufacturer, or otherwise does not necessarily constitute or imply its endorsement, recommendation, or favoring by the United States Government or any agency thereof. The views and opinions of authors expressed herein do not necessarily state or reflect those of the United States Government or any agency thereof. \section{0}




\section{DISCLAIMER}

This report was prepared as an account of work sponsored by an agency of the United States Government. Neither the United States Government nor any agency Thereof, nor any of their employees, makes any warranty, express or implied, or assumes any legal liability or responsibility for the accuracy, completeness, or usefulness of any information, apparatus, product, or process disclosed, or represents that its use would not infringe privately owned rights. Reference herein to any specific commercial product, process, or service by trade name, trademark, manufacturer, or otherwise does not necessarily constitute or imply its endorsement, recommendation, or favoring by the United States Government or any agency thereof. The views and opinions of authors expressed herein do not necessarily state or reflect those of the United States Government or any agency thereof. 


\section{DISCLAIMER}

Portions of this document may be illegible in electronic image products. Images are produced from the best available original document. 


\section{DISCLAIMER}

This document was prepared as an account of work sponsored by an agency of the United States Government. Neither the United States Government nor the University of California nor any of their employees, makes any warranty, express or implied, or assumes any legal liability or responsibility for the accuracy, completeness, or usefulness of any information, apparatus, product, or process disclosed, or represents that its use would not infringe privately owned rights. Reference herein to any specific commercial products, process, or service by trade name, trademark, manufacturer, or otherwise, does not necessarily constitute or imply its endorsement, recommendation, or favoring by the United States Government or the University of California. The views and opinions of authors expressed herein do not necessarily state or reflect those of the United States Government or the University of California, and shall not be used for advertising or product endorsement purposes. 


\title{
ELECTRICAL RESISTIVITY OF STRONGLY COUPLED PLASMAS IN INTENSE FIELDS*
}

\author{
Robert CAUBLE and Forrest J. ROGERS
}

Lawrence Livermore National Laboratory, Livermore California 94550 USA

\section{Wojtek ROZMUS}

Theoretical Physics Institute, Department of Physics, University of Alberta, Edmonton, Alberta T6G 2J1 Canada

It is now possible to measure the electrical resistivity, or alternatively the electron collision frequency, in strongly coupled plasmas through the use of very fast laser pulses. In such experiments, the effect of the intense laser field needs to be included in the calculation of material transport coefficients. We derive a form for the electrical resistivity which includes the effects of strong correlations, as well as an external electric field. Our results are compared with other theories and a recent set of experiments.

\section{INTRODUCTION}

The advent of intense, subpicosecond laser pulses has opened a new window in the study of very high density plasmas ${ }^{1}$. When such a pulse is focused on a solid, much of the laser energy absorbed by the ionizing electrons is rapidly conducted away by cold matter below an absorption skin depth. The result is a cold very dense plasma. The theoretical interpretation of these experiments relies mainly on the electron-ion collision frequency, which governs laser light absorption through inverse bremsstrahlung, and on the electron thermal conductivity, which controls plasma cooling. Given these conditions and the plasma environment, the form of the collision frequency must be appropriate to strongly coupled plasmas in the presence of a strong electromagnetic pump source. Below we take into account both major effects by calculating the electrical resictivity or conductivity, in strongly coupled plasma including the presence of a strong electric field.

\section{GENERAL THEORY}

The electron collision frequency, $v$, electrical conductivity, $\sigma$, and electrical resistivity, $\rho$, share the following relations:

\footnotetext{
"Work performed under the auspices of the US Department of Energy at Lawrence Livermore National Laboratory under Contract No. W-7405-ENG-48 and with the support of the Natural Sciences and Enaineering Research Council of Canada.
} 


$$
\sigma=\omega^{2} p e /(4 \pi v) \text { and } \rho=4 \pi v / \omega^{2} \text { pe or } \rho=1 / \sigma
$$

where $\omega$ pe is the electron plasma frequency. Forms for the plasma $\mathrm{dc}^{2}$ and $\mathrm{ac}^{3}$ resistivity in the case of weak coupling are well known. The bases for these formulations are inappropriate in the presence of a strongly coupled plasma4-7. Attempts to find an appropriate form for these transport coefficients in strong coupling must consider strong electron-ion and ion-ion correlations, electron degeneracy, quantum effects, and completeness of the solution (since most of the final forms are Chapman-Enskog polynomial expansion types). For this calculation, we concentrate on classical statistics in order to elucidate a more complete solution (and include an external electric field). Quantum effects are contained entirely in an effective electron-ion potential and degeneracy is ignored altogether.

We start by writing the kinetic equation for the phase space particle-particle distribution functions, $\mathrm{Cab}_{\mathrm{b}}\left(\mathrm{r}_{\mathrm{a}}, \mathrm{r}_{\mathrm{b}}, \mathrm{Pa}_{\mathrm{a}}, \mathrm{p}_{\mathrm{b}}, \mathrm{t}\right)$, in the disconnected approximation 8,9 , which contains a memory function form of the collision operator; $a, b=i, e$ for point ions and electrons. "Lower order" (analytic) solutions of $\mathrm{C}_{\mathrm{ab}}$ must be used in the collision operator to obtain a solution 10 .

The next step is to "solve" the kinetic equation by expanding in terms of an infinite set of orthogonal momentum polynomials. We assume separability of momentum and configuration spaces, i.e., classical statistics. The transport coefficients are easily recognized by separating the hydrodynamic momentum powers from the remainder of the set. The number of terms retained beyond the hydrodynamical subspace dictates the completeness of the solution. Most of the correction is included by using two additional polynomials 11 corresponding to the so-called two Sonine polynomial approximation. For dc resistivity, the details of this process can be seen in Ref 12 .

For ac resistivity, the time dependence of the analytic $\mathrm{C}_{a b}$ 's must be retained. The simplest correlation propagator Is the free streaming form 10 ; we use this for ion motion. But for electron transport, we take the free streaming correlation modified by the presence of an external electric field. For the two Sonine case where the electric field, $E$, is strong the result is

$$
\rho_{2}(\omega)=\rho_{1}(\omega)-\Theta(\omega)
$$

where $\rho_{1}$ is the one Sonine result, given by

$$
\rho_{1}(\omega)=\frac{n}{\omega_{p e}^{2} \sqrt{2 \pi k T}} \int_{-1}^{1} \mu^{2} d \mu \int_{0}^{\infty} d \|^{3} c_{\delta^{i}}(I) V^{e i}(I) \Delta(I) \Omega(l, \omega)
$$

where 
and

$$
\Delta(l)=S^{\theta \theta}(l) S^{i i}(l)-S^{e i}(l) S^{i \theta}(l)
$$

$$
\Omega(l, \omega)=\exp \left\{\frac{-m}{2 k T I^{2}}\left(\omega+\frac{e E I}{m \omega} \mu\right)^{2}\right\}
$$

The term, $\Theta(\omega)$, represents corrections to the one Sonine case and contains formulae similar to these. Above, $S a b$ and $\mathrm{C}_{D}$ ei are static correlation functions and $\mathrm{V}$ ei is the bare electron-ion potential. In weak coupling, $\rho_{2} / \rho_{1}$ is a known ratio.

\section{RESULTS}

We gear our results to recently published values of the electrical resistivity of solid density aluminum ${ }^{13}$. The plasmas were created by $400 \mathrm{fsec}$ laser pulses. Values of the temperature were derived and presented as a function of the laser intensity. A reproduction of the data appears in Fig. 1.

Our static correlation functions were found in the hypernetted chain (HNC) approximation using a pseudopotential developed by an activity expansion of the partition function 14 . Results for the aluminum resistivity are presented in Fig. 1, along with results from another, completely different method ${ }^{15}$. Lee and More ${ }^{15}$ (L\&M) evaluated $\rho$ by obtaining parameters from the scattering cross section found by a partial wave solution to the Schrödinger equation with the Thomas-Fermi potential. Connections were made to low temperatures. Other calculations, Ichimaru and Tanaka 16 and Boercker, Rogers, and DeWitt 17 , both using Coulomb potentials (not pseudopotentials) and a high temperature limit of the Fermi-Dirac distribution, produce much smaller values of $\rho$. [The latter results are equivalent to the one Sonine approximation and those values in the figure have been reduced by the appropriate ratio. ${ }^{16,17}$ ]

We note llial there is little distinction between our results and L\&M over the range we have calculated, although the curves do not fit the data very well. The closeness is somewhat remarkable since our approach is very different to that of $L \& M$. For the cases here, the degeneracy parameter is greater than one for all but the lowest temperatures, so our calculation should not suffer greatly from nonclassical effects. We have not calculated a pseudopotential for temperatures less than $10 \mathrm{eV}$. For comparison, we have approximated the correlations by their Debye forms and the potential by a screened Thomas-Fermi-like form, which allows an analytic solution.

For most of the data here, there is approximately a $10-20 \%$ increase in the value of $p$ due to assumed intensities of electric fields. We predict that higher laser field intensities can increase the rcsistivity by as much as $50 \%$. Here the presence of the non-zero laser frequency is more important. We note that, when the aluminum is maintained at solid density, none of the calculations predict a $\rho$ as large as the data around $40 \mathrm{eV} \cong 200$ $\mu \Omega-\mathrm{cm})$. 


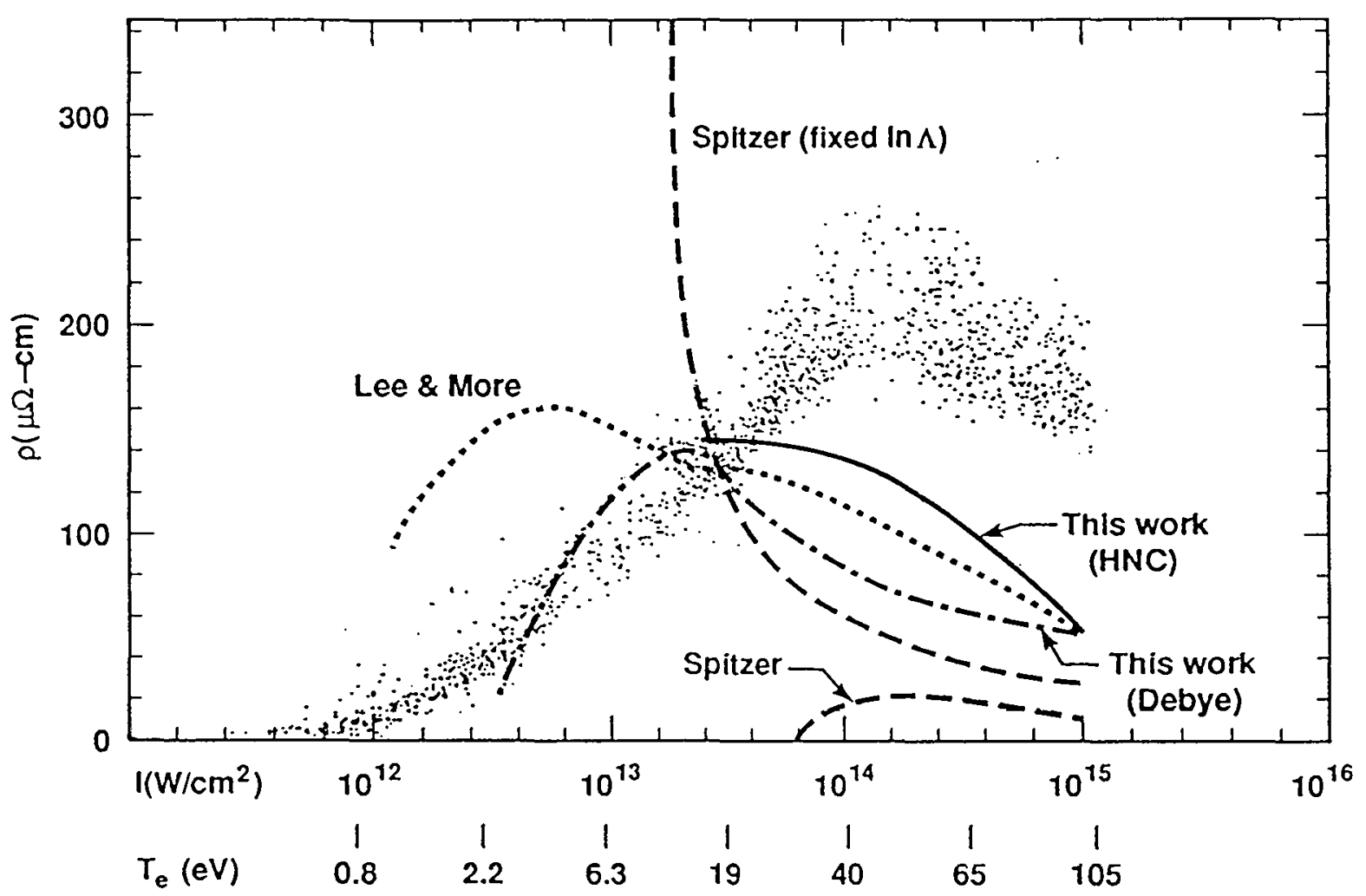

FIGURE 1

Electrical resistivity data from Milchberg ${ }^{13}$ compared with theories of Lee and More 15 and this work with HNC and Debye correlations, as well as Spitzer?

\section{REFERENCES}

1) M. M. Murnane, H. C. Kapteyn, and R. W. Falcone, Phys. Rev. Lett. 62 (1989) 155.

2) L. Spitzer, Jr., Physics of Fully lonized Gases (Interscience, New York, 1962).

3) J. M. Dawson and C. Oberman, Phys. Fluids 5 (1962) 517.

4) J. P. Hansen and I. R. MCDonald, Phys. Rev. A23 (1981) 2041.

5) M. Baus, J. P. Hansen, and L. Sjögron, Phys. Lett. 82A (1981) 180.

6) F. J. Rogers, H. E. DeWitt and D. B. Boercker, Phys. Lett. 82A (1981) 331.

7) R. Cauble and D. B. Boercker, Phys. Rev. A28 (1983) 944. 
8) G. F. Mazenko, Phys. Rev. A9 (1974) 360; G. F. Mazenko and S. Yip, in Statistical Mechanics, Part B, ed. B. J. Berne (Plenum, New York, 1974).

9) J. Wallenborn and M. Baus, Phys. Rev. A18 (1978) 1737.

10) R. Cauble and W. Rozmus, Phys. Fluids 28 (1985) 3387.

11) R. H. Williams and H. E. DeWitt, Phys. Fluids 12 (1969) 2326.

12) R. Cauble and W. Rozmus, J. Plas. Phys. 37 (1987) 405.

13) H. M. Milchberg, R. R. Freeman, S. C. Davey, and R. M. More, Phys. Rev. Lett. 61 (1988) 2364.

14) F. J. Rogers, Phys. Rev. A29 (1984) 868.

15) Y. T. Lee and R. M. More, Phys. Fluids 27 (1984) 1273.

16) S. Ichimaru and S. Tanaka, Phys. Rev. A32 (1985) 1790.

17) D. B. Boercker, F. J. Rogers, and H. E. DeWitt, Phys. Rev. A25 (1982) 1623. 


$$
1
$$

